\title{
Agricultural Productive Public Space: "An Alternative for Increasing Ecological Services, Social Development and Urban Sustainability"
}

\author{
Ignacio Carreno, Wenjun $\mathrm{Ma}^{*}$ \\ Architecture Department, School of Design, Shanghai Jiao Tong University, Shanghai, China \\ Email: ignaciocarreno@sjtu.edu.cn, ^mj@sjtu.edu.cn
}

How to cite this paper: Carreno, I., \& Ma, W. J. (2019). Agricultural Productive Public Space: "An Alternative for Increasing Ecological Services, Social Development and Urban Sustainability". Current Urban Studies, 7, 493-516. https://doi.org/10.4236/cus.2019.74025

Received: June 22, 2019

Accepted: October 8, 2019

Published: October 11, 2019

Copyright $\odot 2019$ by author(s) and Scientific Research Publishing Inc. This work is licensed under the Creative Commons Attribution International License (CC BY 4.0).

http://creativecommons.org/licenses/by/4.0/ (c) () Open Access

\begin{abstract}
The problems affecting major cities are expected to increase under the pressure exerted by climate change, population growth and the incremental nature of urban consumption. Therefore, it becomes necessary to increase urban sustainability and resilience in a way that improves the urban landscape and the lives of urban communities in the aspects of economic income, food vulnerability and the limited access to environmental justice. This study lays the ground basis for the consolidation of a new typology public space through urban agriculture on its different modes (geoponics, aquaponics, geoponics and hydroponics) and derived activities that address the needs of urban centers as it harbors environmental and urban improvement in a profitable way for the stakeholders involved in continuous productive urban landscape. Through a multi-cluster quantitative, and design research, this paper collects the different modes, urban agriculture can be employed in cities and describes a methodology for establishing an agricultural productive public space within the participation of communities, and how it can widen the spectrum of public participation based on a followed-up case study with a community located in the Huangpu district, adjacent to commercial and tourist activities in Shanghai, China. The results of this research represent a methodological approximation for the formalization of the local spatial development with a focus on the participatory approach, for the sake of increasing urban sustainability along with the socioeconomic needs of neighboring communities. The results also evidence the state of consciousness that architecture graduate and postgraduate students have about environmental limits and their conception for the creation of urban value in terms of sustainability.
\end{abstract}

\section{Keywords}

Ecological Services, Resource Harvesting, Urban Sustainability, Urban 
Resilience, Urban Agriculture, Environmental Justice, Public Space, Biomimicry, CPUL

\section{Introduction}

\subsection{Background of Study}

The constant growth of the urban population requires an ever growing food supply that is almost entirely produced in rural areas. This model requires further deforestation of the biosphere for agricultural production as human population keeps growing in number. Currently the amount of all the farmland used on the planet today accounts for an area equivalent the size of South America (Despommier, 2010). Future population growth estimates predict that by the year 2050 the world population is expected to grow to 9.1 billion (UNDESA, 2010). This projected increase in farmland ultimately would require the destruction of more ecosystems to be turned into agriculturally productive land, rendering the agricultural industry as the most pollutant of human activities that ultimately adds on to climate change. Additionally, the current state of the urban habitat and the expected pressure exerted by diverse factors affecting cities such as continuous migration from rural areas, environmental destruction, climate change, food shortages, the spike in food prices (Abdolreza, 2011; World Bank, 2012), energy production, waste management, $\mathrm{CO}_{2}$ emissions, the need for access to health care and education are only expected to increase in the future (Parikh et al., 1991).

Although, many of the problems that affect urban sustainability lie in the current agricultural paradigm. It would be critical to make a change in the paradigm considering that urban centers are the final destination of the vast majority of agricultural production, in order to increase the sustainability of cities which also leave an indelible impact on terrestrial ecosystems. In doing so, initiating a transition from rural to urban agriculture areas would require new intervention frameworks and spaces for urban agriculture to be accepted as a new element of the built landscape; a space to develop new ways to increase urban sustainability by propitiating changes in the dialectic relation between sustainability and urban development (Ayman, Weaam, \& Khaled, 2013). But, the rising price of land near urban business centers had affected the ratio of available open public space that can provide ecological services and bolster human development. Thus, affecting the radius of influence of these spaces is not large enough to have a positive impact on communities or neighborhoods in vulnerable conditions and this severely affects their access to environmental justice (Fadiman, 2016; Shen, Sun, \& Che, 2017).

Accessibility is pivotal for the development of new inclusive urban scenarios for urban residents to participate as citizens that have a right to the city, but these spaces have been affected in number and size since the XIX century and 
most of the XX century (Sennett, 1977). Due to the impact of commercialization and capitalism, it further affecting the configuration of spaces for social interaction and the resulting spatial inequality as well a diminished urban sustainability and urban resilience (Harvey, 2008). In an effort to increase sustainability, some cities had started adapting urban and peri-urban agriculture in different modes but not without its barriers and limitations to be considered entirely successful in raising urban sustainability or human development. There is also the accessibility issues associated with having large green open far away from city center areas where they are most needed and the commodification of available urban space limits the expansion of public areas and of the inclusive urban agriculture (UA) (Mc Clintock, 2010).

On the other hand, the notion of urban agriculture improving food access and availability originates from capitalist conceptualization of access. A literature review of urban agriculture and food access evidences the way the increased supply its mixed with the existence of urban farms, without analyzing where the food goes and its consumed and where related profits end up (Siegner, Sowerwine, \& Acey, 2018). It is important to link urban communities to urban agricultural production and management of theses spaces so they can benefit from profit and produce consumption. Urban agriculture holds great potential to increase urban sustainability, to lessen the burden cities exert on the ecosystem as well as improve conditions on the urban landscape, offer potential for community development (Akemine, 1999). Additionally, by reducing rural agricultural production through an increase in UA, rural farm fields could be allowed to bounce back to their former natural state and ultimately reducing the effects of global warming by increasing $\mathrm{CO}_{2}$ sequestration (Despommier, 2010). Another benefit of UA alternatives is the use of urban soil or rather the absence of it. Contaminants such as organic chemicals, asbestos and heavy metals are present in the urban soils of large cities such as the city of Shanghai (Delang, 2017). Therefore, agriculture in urban soils can represent a risk to human health by growing agricultural products for later consumption in polluted urban soils (Kim et al., 2014). However, traditional geoponics still have a role to play in the improvement of urban ecological conditions through horticulture, urban forestry and gardening as many vegetal species can gradually clean contaminated soils and the air during the process (United States Environmental Protection Agency, 2011).

To further exploit the benefits of UA, it is required a series of changes at an urban and social level to be implemented. Architecture has the capability to influence culture and society in a self-referential cycle (Schumacher, 2010). It can trigger a cultural change toward consumption and our relation with the environment, but it may take decades to develop. The adaptation of existing cities must be done gradually. Adapting cities requires small localized interventions instead of the tabula rasa approach. Small, organic, localized urban acupuncture interventions that would cater to social, economic and environmental needs of a target community whilst increasing urban sustainability would be the most 
suitable and sustainable approach (Pawlyn, 2016). Therefore, the relationship between architecture, public space with urban agriculture as a source of ecosystem services gains relevance as together, have the potential to minimize the environmental cost and the pollution associated to agricultural production in rural areas and its consequent transportation to their urban distribution centers (Despommier, 2010: p. 95).

From all the different modes on which UA can be carried out in an architectural space, vertical farming (VF) comes as a step forward toward a more efficient UA practices for the next century. Represents greater agricultural yields on very little space at a fraction of the costs associated with traditional rural agricultural geoponics. It could revolutionize the current agricultural paradigm. But since the 1990's, VF has had little hold as a practice today it's because most VF ventures had winded up in failure for most private ventures. Among the causes for the stymied progress are the low performances, the high investment cost, about USD 6217.22 per square meter of vertical farm and an initial investment that ranges from USD 4 to 7 million (Tasgal, 2016). Additionally, to the aperture costs, the operational cost affect the earnings keeping the profit low in addition to the labor costs and the expensive equipment necessary for running operations. The common denominator of these causes is the hermetic closing and automation associated to VF operations that raises production costs, lowering profits (Michael, 2017). This airtightness obeys temperature control and protection protocols against pests and other vectors. VF as widely popularized by Dickson Despommier; works in a close loop system which limits outside world's contact with the system (see Figure 1). But, by closing it off, it generates a space that denies access to the city, thus generating a "Non place" (Auge, 1992); a place of no individual significance or interaction for urban residents. Thus its potential to foster human development is null at best.

The closing off VF has stymied the dissemination of the practice and as urban land value raises so do the operational cost for the most technified UA modes. This poses great obstacles that needs to be addressed because there is lack of wide recognition of this problems and of the alternatives of how to approach the issues with V.F on current available literature. For the reasons stated it can be hypothesized that V.F would greatly benefit from opening its doors to urban farmers (Besthorne, 2012). As manual work and stewardship would drive the

Limited participation

\section{Technological complexity}

$\begin{array}{lllll}\text { Communal } & \begin{array}{l}\text { Residential } \\ \text { building } \\ \text { rooftops }\end{array} & \begin{array}{l}\text { Community } \\ \text { hybrid }\end{array} & \begin{array}{l}\text { Rooftop } \\ \text { greenhouse }\end{array} & \begin{array}{l}\text { Vertical } \\ \text { farming }\end{array} \\ \text { Community participation } & & & \\ \end{array}$

Figure 1. Complexity spectrum of urban agriculture. 
high operational cost down. Given that the airtightness component should be more permeable to allow accessibility, certain concessions on both parts of the spectrum should be made, meaning that the design of such space should consider the requirements for both vertical faming and community involvement in new urban agricultural practices as well as sustainable design principles to keep operations at a minimum carbon cost.

\subsection{Aim and Objectives of the Research}

The research aims to describe and determine the necessary role of a new agriculturally active public space that provides environmental services and options for human development that can highlight significant issues of human sustainability and sustainable development.

Highlight the role of the public space through the origin and evolution of the city as an inclusive space necessary for the environmental needs of the individual. Propose the possibility of transferring agricultural production as close as possible to its final distribution sites in order to start mitigating the future social, economic and environmental burdens foreseen for the year 2050 and beyond.

This paper aims to develop a theoretical framework that can fit within the vision of the Continuous Productive Urban Landscapes and the advances made in Vertical Farming in relation with Social Work, participative design and Sustainable Urban Agriculture.

This theoretical framework will lead to the development of agricultural productive public spaces. So that these can be considered as a lucrative investment for the stakeholders involved; in order to expand its influence as a concept that is widely accepted in the cities, desired by the communities considered by designers and urban advisors.

This research draws connections between the principles of sustainability associated by vertical farming in the writings of Despommier and the design work of architects such as Stefano Boeri, Cedric Price, Michael Pawlyn, Sou Fujimoto, Ken Yeang and the team of architects in ecosistema urbano: Belinda Tato, Jose luis vallejo, Diego García-Setin. As well as attempts to integrate their work in urban Agriculture and the betterment of the urban environment with the work of Besthorn's (2012) and Calderon's (2012) by linking it with Social Work's Environmental Legacy.

This paper also aims to disambiguate the definition of vertical farming as it is mistakenly referred to as growing agricultural produce in a vertical fashion. And not as the growing of plants under controlled automatized conditions, air tightness, lighting requirements or the growing medium (aeroponics or hydroponics).

The following are the specific objectives of this study:

- To draft an architectural program that integrates urban farming, vertical farming made open to community stewardship, urban and community development. 
- To create an architectural object that can influence user perception towards urban farming and urban sustainability and encourage more sustainable habits.

- To raise awareness of the problems associated to rural agriculture and the benefits of moving agricultural practices to the urban landscape.

\subsection{Methodology}

For this study a design research was conducted in a three stage process divided into two simultaneous work clusters (see Figure 2). The first stage opens with the first cluster. An individual process based research that used qualitative methods used to gain an understanding of potential and the underlying causes of the problems affecting vertical farming and how affects urban agriculture, and evaluating data through the literature analysis, that conducted to the hypothesis and data recollection for both the second stage and work cluster of the research effort. For this stage were also employed empirical methods as site observation, interviews and a focus group meeting.

The second stage and cluster was a design workshop based research that follows on the data collected on the first cluster. Through quantitative methods and with the help of the students from the Strategic Design for the Enhancement of Architectural, Urban \& Environmental Resources summer course of 2018 at the Shanghai Jiao Tong University. Demographic data was collected via field surveys and analyzed to find intervention patterns. Through surveying the inhabitants,

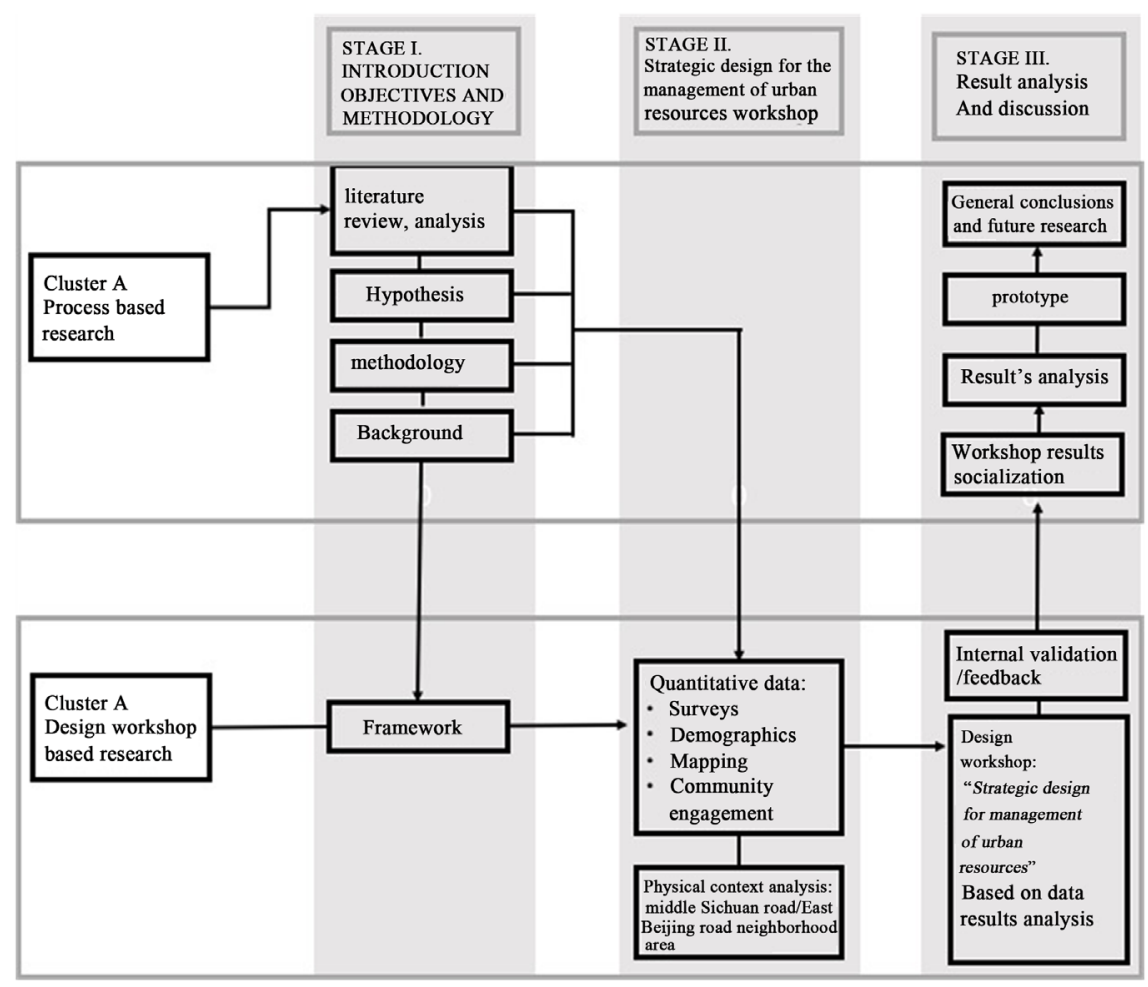

Figure 2. Methodology structure. 
pedestrians including plant identification and residence type, mapping, survey questions for the inhabitants including semi-structured interviews to gain a better understanding of whether the participants resided in the area and if so for how long, their gender, ages and occupations, and whether they consumed the food they grew.

Finally through a design workshop based research, the students structured a proposal in the case study of the community surveyed. For the case study, it was chosen a near commercial business district (CBD) plot located in the intersection of two roads; middle Sichuan road and east Beijing road in the city of Shanghai, China. The community living in the vicinity lacks access to environmental infrastructures and their associated benefits. This area also lacks grocery stores, farmers' markets, and healthy food providers. This absence of food availability creates a phenomenon known as a food desert (Gallagher, 2018). The unavailability of whole food suppliers nearby in a way encouraged the residents to attempts to make up for this by absence, engaging in farming, horticultural practices in whatever residual space available in their residential units. The third stage return to the firsts work cluster to employ a thematic process research approach to scrutinize through the feedback collected on the previous stage by the second work cluster. In an explorative and empirical design process a vertical agricultural productive public space design (V.A.P.P.S) is drafted as an object to meet the premises stated in the hypothesis.

\section{Space for Urban Sustainability}

This research draws a framework for a new open public space that addresses the issues affecting the cities of today and in the near future as well as the condition that threat the safety, resilience and sustainability. As urban centers are the largest consumers of agricultural produce from rural areas, it would be ideal to consider agricultural production in cities in order to reduce further pollution and destruction of earth's ecosystems and to mitigate the effects of global warming. These conditions had increased the vulnerability of major urban centers and it's only expected to increase under the pressure exerted by population growth, resource exploitation and global warming. Former UN Secretary-General Ban Ki-moon's remarks have a profound importance in the context of global sustainability as he addressed a High-level Delegation of Mayors and Regional Authorities in the city of New York. During this summit he pronounced that "Our Struggle for Global Sustainability Will Be Won or Lost in Cities”. As cities are public scenarios and epicenters of most anthropogenic activities, urban centers must secure sustainability in social, economic and ecological terms while preserving historical elements in physical manifestations influenced by cultural conditions to so it can be preserve in people's imaginaries. Public spaces can provide places where urban dwellers can gather and engage in programs that reflect their cultural background.

But as urban population grow, and urban density rises, open public space di- 
minishes along with urban sustainability. So it can be inferred that there is a correlation between the open public space and urban sustainability. The definition alone of urban sustainability still entangled among the different fields on which it expands and develops different yet similar interpretations, very commonly associated to the economic, social, and environmental, where efforts are focused on the economic and environmental aspects rather than the social. Urban sustainability had been added new concepts such as Ecosystem services, community well-being and development and low carbon (Brown \& Jameton, 2000), to create the smallest possible ecological footprint and to produce the lowest quantity of pollution possible while advocating for community development. This collage of utilities, requirements, and uses reflects the need for fluidity contemporary urban environments and the structures that support those changes.

\subsection{Urban Agriculture and Open Public Space}

Levi-Strauss stated that "public space must find its way between structure and event" (Rowe \& Koetter, 1978). Just as with public space, UA must find its place between the structures of public space and the rich environment of localities. UA can add to that collage of requirements, potentialities and events. Urban agriculture involves the production of food in urban environments and offers a proper equitable and inclusive opportunity to build up and increase resilience in cities. It has been present ever since cities first appeared. There's evidence of UA since ancient Egypt where plots were cultivated within cities (Janik, 2002). In the 20th century through north America and Britain during both world wars with the victory gardens which vastly improved the cities' resilience during the periods of food shortage (Herrmann, 2015).

Urban agriculture offers different benefit to the urban landscape such a: waste management benefits, resource conservation, disaster relief, mitigation and relief in natural, civil, and economic crises, abatement of air pollution, improved climate and associated energy savings, biodiversity increase and conservation and environmental enhancement (Nasr, Ratta, \& Smit, 2001).

\subsection{Harboring Urban Agriculture}

There are different ways to provide ecological services to the city, open public space alongside with urban agriculture offer a myriad of different but associated ways; gardens, orchards, lawns, arboretums, greenhouses, hydroponic, aeroponic facilities and Vertical farming. The later represents an efficient way to increase urban sustainability in limited areas such urban centers where the areas available for the establishment of open public space tend to decrease in quantity and area. However due to the air tightness of VF, its accessibility is limited or off-limits for individuals, communities and vulnerable populations out of its sphere of participation. But, the relevance of vertical farming besides been a mean for increasing food security, job creation, environmental improvement and shorter chains of 
supply $^{1}$ (food miles) (Pollack, Wood, \& Smith, 2010); Lies in its potential to maximize land area and surface by going vertical specially near city centers where land value is increasingly more expensive. However, VF had encounter obstacles along its way that most publications on the matter fail to address. Issues like the elevated investment requirements, the great electricity demand and the high cost of operations within these facilities (Perez, 2014). The potential to solve these problems lay in "democratizing" VF as an UA practice, turning it into a more accessible option for UA instead that a highly technical one. Linking VF to public space can democratize the practice will allow for community stewardship thus lowering operations cost as some technical requirements may be replaced by manual labor performed by participants. Labor that can be remunerated economically or axiologically with the access to ecological services and healthy, organic agricultural produce a part of the remuneration. For the immediate context of this study, the city of Shanghai, the willingness to engage in urban UA is present among the residents. It is known that Horticulture is rooted in local Chinese culture as folklore ties gardening stewardship with a sense of fulfillment and happiness (Phillips, 2006). In addition, communities will also benefit from vertical farming as construction workers would be needed as well as maintenance workers, grocery stores, markets, restaurants, local distribution networks (Despommier, 2010: pp. 227-228). Public space can be used as the matrix where urban agriculture can develop into a viable tool for urban, social and environmental improvement where urban dwellers connect their own cultural activities on an open public space in a way that their activities and leisure enhances their quality of life (Poe, Lecompte, Mclain, \& Hurley, 2014).

This concept belongs to a field of theory and praxis focused on integrating UA permanently and in a profitable way into the urban landscape while tying VF to community participation by placing it in a public place accessible to everyone without restrictions or control barriers (Nasr et al., 2001: p. 11).

\subsection{New Approach to Open Public Space}

In China, the decade of 1980 saw the apparition of new typologies of public space that brought the people and the state closer (Huang, 1993), opening the door to the dissemination for new spatial structures in modernity withal the associations it implies, such as the space for spontaneous, un-programmed but organized collectives (Gaubatz, 2008). It was during this decade that the city of Shanghai experienced an increase of its green space area, mostly due to Deng Xiaoping's socialist spiritual revolution that re-emphasized on the "consumption of space rather than the production of one for an egalitarian working community/city" (Choi, 2016). Currently the city has 34,300-hectare worth of green spaces, approximately $16 \%$ of its area (Li, Wang, \& Song, 2008). But this percentage is overshadowed by the scale of the city and its associated environmental impacts

${ }^{1}$ In the United States alone food miles account for $20 \%$ of the consumption of fossil fuel. 
and the fact that in most parks in Shanghai are composed of lawns and the access to lawn areas is forbidden. Most lawns are corded off from the public and visitors are aware of the parks laws and respect them. Restriction on lawn access affect how park goers use the public space and by been excluded from portions of the park physically. It generates has a sociological effect that evidences systematic obstruction to environmental justice and diminished ecological services as monocultures require more water, grooming and pesticides than native vegetation (Porter, 2011). So switching away from lawns to increase ecological and agricultural output should be a priority as vulnerable communities would see their access to environmental justice improves by integrating them into a community stewardship plan for a vertical public open space with a mixed program where lawns are replaced with agricultural plants and native flora for horticultural use.

\subsection{Components of Public Space}

Historically, public space has been a tool for raising urban sustainability and a medium for preserving the natural landscape dating back to the XIX century (Almansuri, Curwell \& Dowdle, 2009). Through time, public space has reflected the diversity for urban centers and encouraged people to live together, generated the necessary conditions for people seek out to be outdoors. It is the vitality of these spaces that attracts people. What guarantees this vitality is the possibility of enjoying urban spaces in various ways that cannot be experience indoors otherwise. This enjoyment and accessibility inherent to public space condenses social, cultural and environmental elements that seek to respond a need of ecological services. Considering the longing for an environmental medium to break the routine marked by artificial surroundings, different elements are required to stablish an open public space, a wide variety of activities and different spaces would have to be offered to cater to the diverse spectrum of users regardless of gender, age, income, education level or precedence (see Table 1). The openness for an agricultural productive public space requires to be conjugated with verticality in order to maximize the space available for a diverse and inclusive program. The aesthetical and spatial exploration will generate a positive use of space and increase urban vitality and the mixture of services contemplated in the architectural program should cater to the needs of residents, workers and commuters in a way that physically active means of transportation (walk, run, jog, bicycle, etc.) are encouraged. Studies suggest that the lack of facilities and infrastructure dedicated to the practice of active commuting discourages the practice of active commuting. Considering that the area is rather close to the CBD and close to touristic and commercial landmarks of the city. It is desirable to have adequate services for active commuters to ready themselves before they get to their jobs, thus discouraging the use of motor vehicles which translates into less pollution and promotes healthier life styles (Balamou, Efstathiadou, Maimaris, Papageorgiou, \& Xergia, 2018). 
Table 1. Elements present in green open space.

\begin{tabular}{cccc}
\hline Components & Park & Garden & Farm \\
\hline Strategic location & $\mathbf{x}$ & $\mathbf{x}$ & \\
Enhance landscape conditions & $\mathbf{x}$ & $\mathbf{x}$ & $\mathbf{x}$ \\
Connection to other areas & $\mathbf{x}$ & $\mathbf{x}$ & \\
Strengthening of the sense of the public & $\mathbf{x}$ & $\mathbf{x}$ & \\
Enhance landscape conditions & $\mathbf{x}$ & $\mathbf{x}$ & $\mathbf{x}$ \\
Water management & $\mathbf{x}$ & $\mathbf{x}$ & $\mathbf{x}$ \\
Vegetation in landscape units & $\mathbf{x}$ & $\mathbf{x}$ & $\mathbf{x}$ \\
Hardscape & $\mathbf{x}$ & $\mathbf{x}$ & $\mathbf{x}$ \\
Stewardship & $\mathbf{x}$ & $\mathbf{x}$ & $\mathbf{x}$ \\
Ecological services & $\mathbf{x}$ & $\mathbf{x}$ & $\mathbf{x}$ \\
Plant consideration & $\mathbf{x}$ & $\mathbf{x}$ & $\mathbf{x}$ \\
Physical activities & $\mathbf{x}$ & & \\
Agricultural produce & & $\mathbf{x}$ & \\
Horticulture & & &
\end{tabular}

The availability of urban of scenarios that stablishes connections with urban habitants its crucial for livability as this spaces connect to people and makes them feel proud of their neighborhood and of their city; as they make them more enjoyable. Such was the case for the impoverish neighborhoods or "comunas" of Medellin, Colombia; where the creation of new urban equipment and public space triggered a positive social and economic change that improved these dynamics without gentrifying the neighborhoods (Calderon, 2012). This kind of interventions that uphold community interest and their participation throughout the design process generates a social dynamic localized in an urban landscape where people are encouraged to take an active role and bolster a sense of ownership and stewardship, and thus resignifying the area, endowing it with a new significance that reflects local identity, social participation and stewardship; all central elements for the construction of safer, equitable public areas.

Public space attends various types of elements that are part of the urban context. All factors considered, the development of a sustainable public space must use elements to configure the space strategically for the success of the intervention. These elements can be divided into physical components, cultural components, and ecological components (Kim \& Kwon, 2018: p. 21). To this categorization a fourth component is to be added, the agricultural component that would be the productive and resource harvesting element (see Table 2). Both necessary as part of the personal, social and economic transformations that sustainable design uses to generate collective wellbeing in individuals with a low impact on the environment where zero impact is the most desirable goal. 
Table 2. Kim \& Kwon's categories of sustainable component with an added proposed agricultural productive component.

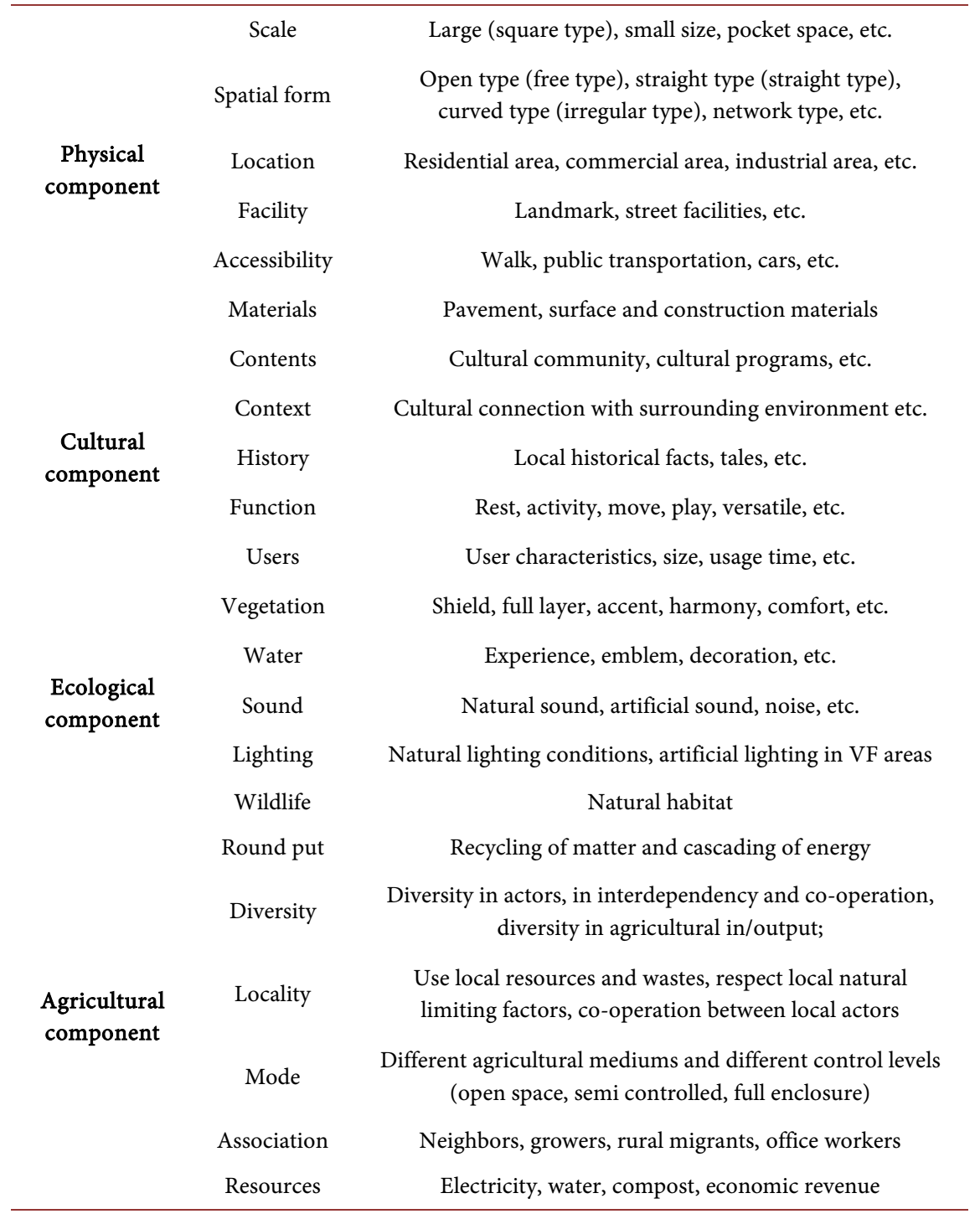

\section{Results}

\subsection{Community Engagement, Reception and Response}

The case study took place in the area located in the intersection of middle Sichuan road and east Beijing road in the city Of Shanghai-PRC (see Figure 3). The initial approach consisted in a survey designed aimed to corroborate the willingness of the residents to engage in urban agricultural activities (Ozak, 2015). The data revealed that most residents grow plants and vegetables in whatever little space they have available for such an activity; in most cases they do so in alleyways or in makeshift gardens they adapt from a residual space within their residential units (see Figure 4). Also as part of the survey, the residents were asked about their perception of their community, the positive and the negative aspects they would like to improve upon. On the positive side, most 


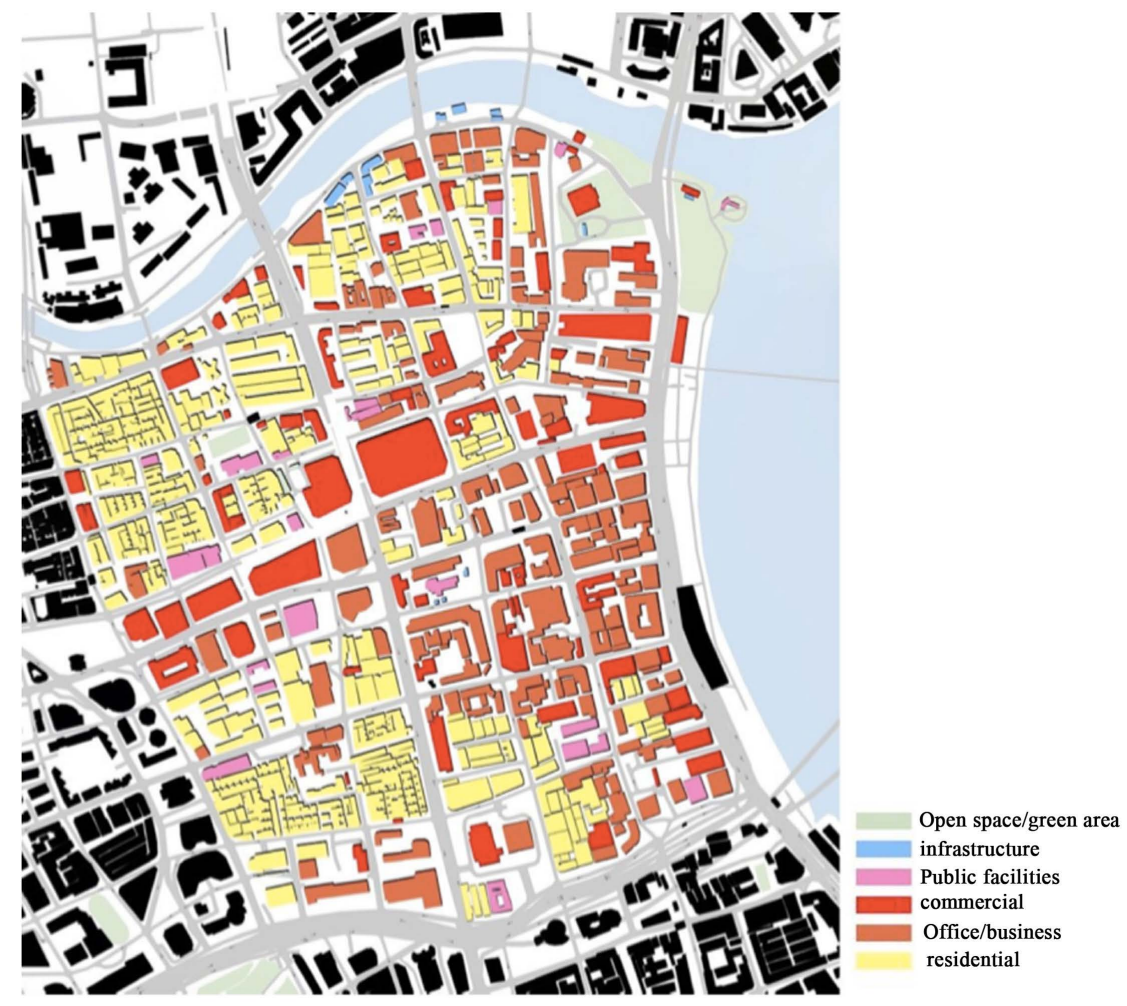

Figure 3. Urban reading of the middle Sichuan road and east Beijing road neighborhood area.

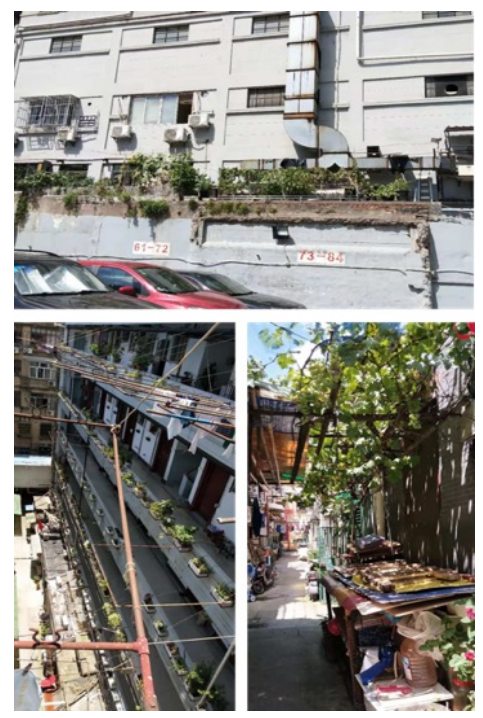

Figure 4. Agriculture horticultural manifestations of the residents in the areas adjacent to the study site.

agree on the location of the neighborhood, the visuals and the available sunshine and wind currents present in the area. As negative aspects, the residents all agree on the living conditions. Both residents of high rise and ${ }^{2}$ lilongs (Ruan, Zhang, \& ${ }^{2}$ Lilongs, are residential areas that date back to the Han and Tang dynasties where residential areas were houses were clustered and aligned alongside alleyways for a more convenient management. 
Zhang, 2014) are not satisfied with the state of their residences. Some of them are long overdue for restoration or renovation. This is due the fact that buildings are old, some of them dating back to the decade of 1950's. And many are catalogued as architectural heritage of the city, which means that the renovation or restoration of these buildings and their adjacent edifications are under strict regulation.

From the 18 people questioned, 8 were men and 10 women whose ages range between 30 to 70 years old. The absence of younger residents was explained by the residents as the area is old and lacks the potentialities of other areas in shanghai. The residents also mentioned among the surveyed residents, all grow ornamental plants, $61 \%$ percent grow their own produce for their own consumption alongside the ornamental (see Figure 5). Participant students also

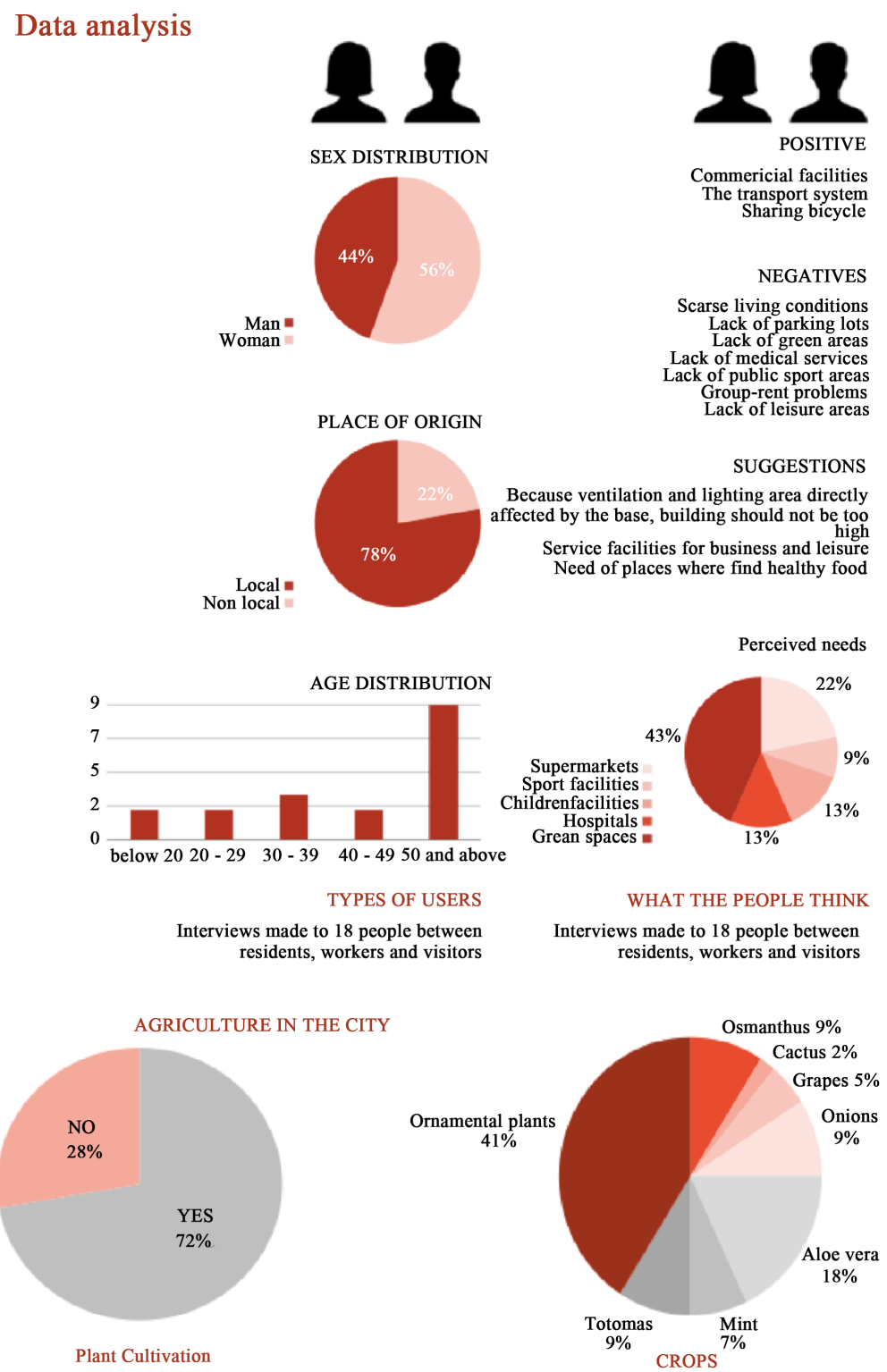

Figure 5. Survey data results. 
socialized the idea of offering an agricultural productive installation that hypothetically would offer access agricultural production mediums (soil, hydro/aeroponic systems). The acceptance rate of such hypothetical structure was rather high among residents and workers of the area who also expressed their willingness to participate in a community garden.

As observed, agriculture is part of the daily lives of the residents of the area; although they practice it on a domestic scale, in isolated interventions. The perceived need of supermarkets to supply their kitchens of agricultural produce, the perceived lack of open green spaces the need to have greater accesses to a more convenient food supply as well as for environmental services are accounted as the reason that motivated the survey participants to engage on the agricultural/horticultural activities.

Additionally, as part of the engagement workshop participants learned of basic notions of urban agriculture, alternative means to grow food in urban areas with reduced space and the possibility to improve their economic incomes by selling part of their production to local markets and restaurants. The residents all expressed their interest in these new productive alternatives and manifested their willingness to participate in vertical urban agricultural scenarios if provided with one.

\subsection{Design Strategy}

\section{Architectural Program}

Considering the wide spectrum that encompasses sustainability, it is important to create a programmatic appropriation of the place by the community in order to maintain low operating costs and achieve a high rate of maintenance of the site as well as increasing community access to environmental services together with an improvement of the environmental conditions of the area in which the new vertical productive spaces are located. To achieve this, vertical public space designers have to consider cultural and ecological interactions in order to stablish a physical permanence as an environmental-social condenser. A potential architectural program should be conceived in terms that include practices tied to human development but also forms of well-being and promote social bonds, community building, social support, and urban infrastructure renewal (Kim \& Kwon, 2018). The design for a new sustainable public space must solve all the variables that affect public space and offer a dialectic response derived from the local, immediate contexts and the design approaches of a global city (see Figure 6).

\subsection{Parameters}

Having compiled and analyzed the data gathered and considering the needs of the community studied, it is important to set the set of design parameters and determinants that will rule over the design process in line with the aim of the study to reach the objectives stablished. 


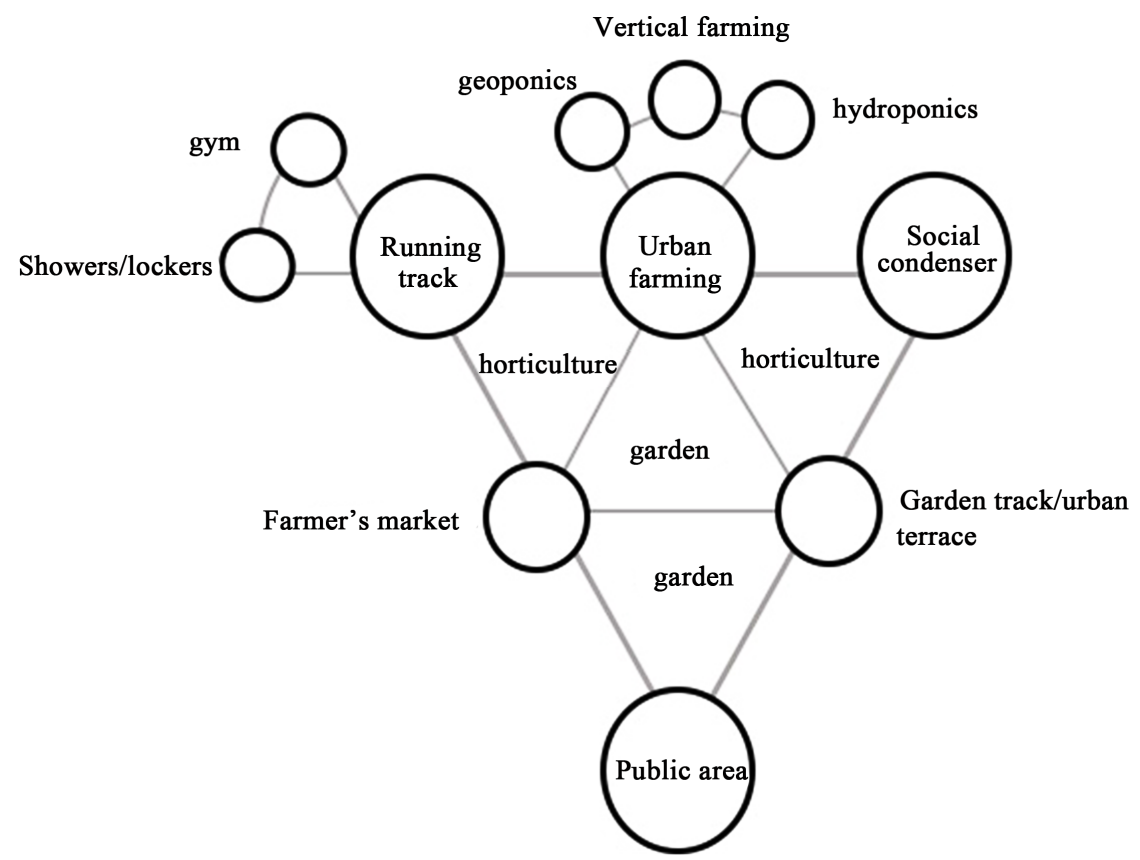

Figure 6. Architectural program/relational scheme.

Achieving increased urban sustainability and resilience it's only achievable through strategies that prioritize sustainability over stylistic concerns. As Toshiko Mori puts it, "Architects and other citizens must actively make choices about where build, what to build, how to build, and with what to build" (Plasencia, 2019). In this regard, sustainable objectives are part of the design program to help achieve real sustainability through the inclusion of Agriculture to urban society in a procedural way (see Figure 7). This to set a methodological precedent to avoid following interventions that propitiate; "telescopic urbanism", a fast form of implementing buildings or public space that have little to do with scale, neighborhoods or the social fabric (Lancione, 2013) and with communities such as the one in this case study there are cases of new commercial and tourist enclaves that appear disconnected from their residential context, creating a rupture rather than an approximation. That could have been inserted in a more sensitive manner toward the neighboring communities than the way they were implemented and stand today. Turning residents into stakeholders, actors vie inclusion in different design and decision making stages guaranties acceptance, and betters the chances of occupancy and use of installation (Imparato \& Ruster, 2003).

\subsubsection{Sustainable Design}

The Brundtland commission defined sustainability as "the development that meets the needs of the present without compromising the ability of future generations to meet their own needs". This deals with all aspects of society, the economy, culture, politics, technology, transportation and agriculture. This definition involves architecture closely as a human cultural construct and medium 


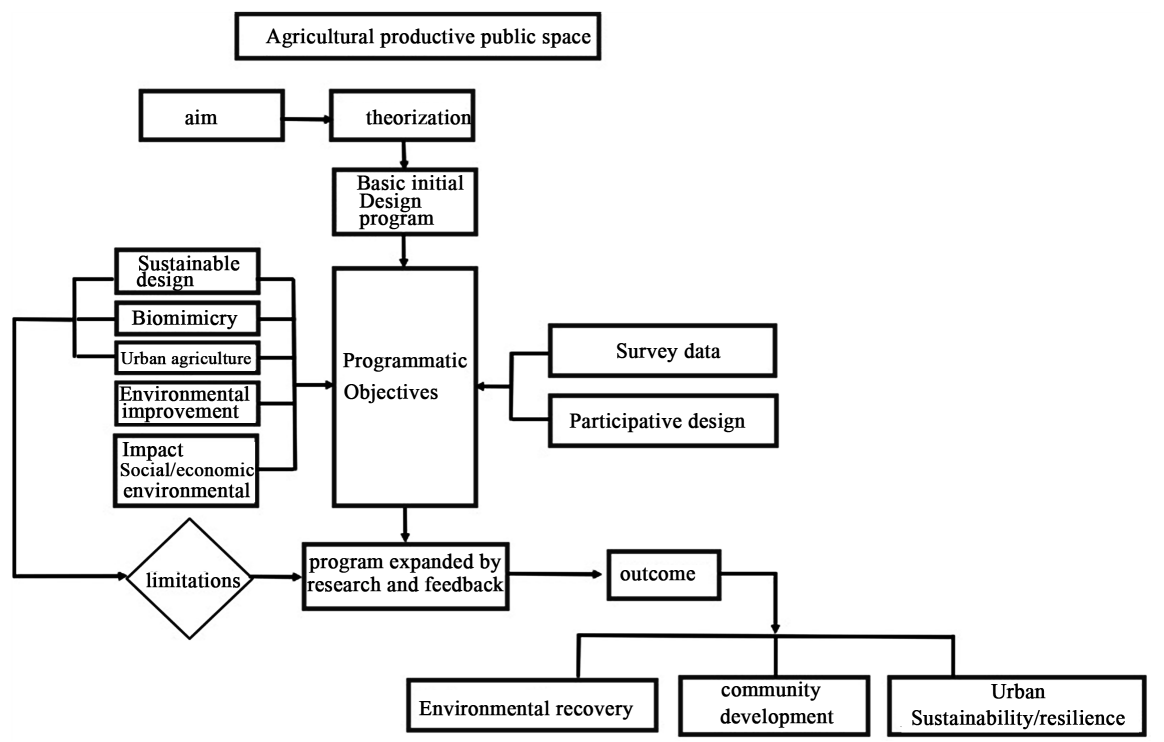

Figure 7. Agricultural productive public space framework.

where the economy, history, culture and society are represented (Robinson, 2006). Along these lines, sustainable design is defined as "a design philosophy that seeks to maximize the quality of the built environment, while minimizing or eliminating negative impact to the natural environment" (McLennan, 2004). This definition in particular favors sustainability as a doctrine, a philosophy rather that a trend or a stylistic exercise. This notion of sustainability as a philosophy implies for direct involvement of users during different stages of design process. Professionals combine their skills with sustainability awareness to design Sustainable solutions to meet different needs such as environmental, safety, accessibility and inclusiveness without compromising functionality or profitability while minimizing energetic consumption and carbon. One of the ways on which urban agricultural public spaces can help increase urban sustainability is the one already mentioned; reducing environmental impacts of rural farming, but additionally by turning waste into inputs of a productive agricultural system. For this, biomimicry offers alternatives by applying nature's successful evolutionary patterns and strategies.

\subsubsection{Biomimicry}

The strategy for a sustainable design seeks to maximize the efficiency of the resources available; energy and land area available through verticality; this poses a technical challenge as natural illumination and hydric resources are most required for ecological. Design researchers have found in Biomimicry a wide array of solutions for environmental sustainability and resource harvesting. Biomimicry is the design inspired by the way of how nature had solved challenges through millions of years of evolution. It is often referred by circular economy advocates as a systematic approach to enable the transition to a world that is regenerative, accessible to all and abundant in resources (Pawlyn, 2016: p. 5). Bio- 
mimicry applied to architecture consists in using nature as a model take inspiration from natural designs, processes them and applies them into the built environment, using nature as measure standard. In this way, metrics such a carbon sequestration, oxygen production, water storage capacity, filtration and evaporation, can be set to measure the efficiency for what is be built (Pawlyn, 2016: p. 129). Today it has gain momentum as researchers from different fields had figured ways to harvest resources from the environment at a cero energetic cost passively by adapting nature's strategies for harvesting resources such as food, energy and water.

\subsection{The Proposals}

The students participating in the design workshop drafted 4 different prototypes (see Figure 8) that covered the same principles of sustainability and creation of urban value but with a more flexible architectural program in order to propose new uses for public spaces. In this way it is expected to generate different ways of increasing the capacity of the interventions to become spaces of social and environmental participation. Social condensers that their continuous occupation contributes with activities aimed towards the sustainability of the sector and by addition, of the city.

All participant groups had different approaches to reach the workshop objectives, raising urban sustainability and ecological services through urban architecture. Even though aim was stablished by the workshop parameters. The conception of urban sustainability was different for each and every group. This obeys the wide spectrum that comprehends urban sustainability and all the fields and areas that it involves.
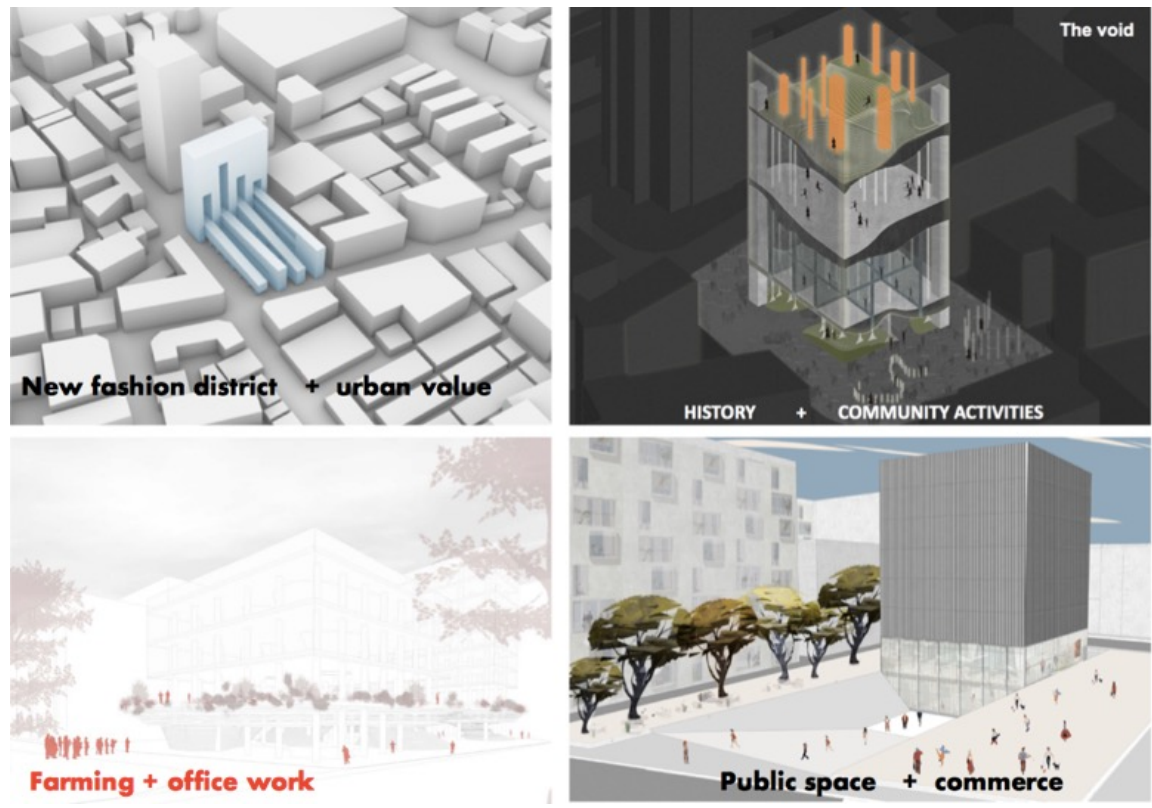

Figure 8. Design workshop prototypes. 


\subsubsection{Group 1}

Group one sought out to protect local features (space and social) at the same time that seek to trigger cultural and economic investments to attract people, by generating a new identity (global-local) with the prefiguration of a city creative hub that cater for design and design enthusiasts, a fashion district.

The group aimed to recover some significance and attention from the public sphere back into the area by means of gentrification. However, it was not clear how the proposal as a fashion district would help to increase other aspects of urban sustainability other than the economic side. As the environmental and the social would not benefit at all or in contrast would be affected negatively. The process of generating urban value economically and statically are core values held in high regard in architecture faculties, however allocating little concern for social and environmental need specially if contextualized to the immense pressures exerted by the threat of global warming suggest a disconnection between practice and context.

\subsubsection{Group 2}

The second group opted for a more inclusive approach as labor force goes. Their design is aimed to cater to all the different kind of workers around the area (from manual laborers, retail workers, office workers and golden collars). Following a geometry suggested by the urban reading of the surroundings, group 2 arranged an array of small to medium size public spaces indoors and outdoors to articulate the rest of the functions inside. Offices and commerce where all spaces and corridors are in direct contact with a green area.

This proposal involves economic recovery and the need for increased ecological services access and output. Offering an inclusive approach to different level workers in a multi-level area of the city guarantees occupancy to some extent. Additionally, by tying it closely to green space reinstates the importance of green space in the urban reality and how the environment could be tied to all activities and all incomes. Offering the option of disconnection from "hyper connectivity" that absorbs the individual from the public sphere

\subsubsection{Group 3}

Group three decided to tackle the lack of public building in the area that drives young residents and young families away to areas were those need can be met. As discussed in the results part of this research, the residents of this area expressed their concern for the lack of public equipment and spaces for social interaction, so in order to configure a more inclusive space for the residents and to fabricate spaces where they can interact among themselves and adjacent communities.

This project focuses on social sustainability and community development. It offers spaces where the state can assert its presence in the community by providing new infrastructure aimed for communities. As previously discussed in this research, public space is a medium that brings people and the state together. 
It also offers spaces for people to have a direct access to green spaces and ecological services and aesthetically reconciles the alloy composed by different architecture styles and heights in the area.

\subsubsection{Group 4}

This group opted for addressing the rich historical and cultural background of the city and the role of the Huangpu area throughout the decades and centuries in Shanghai. Reconcile the lack of awareness that a high tourist flow area as this one has with the rich, harmonious history of the locality. It seeks to connect with local residents and workers with to learn and enhance from the unique architecture background.

The proposal aims to integrate historical divulgation of the area in different levels, areas and spheres so the city, the area and tourist can add to the experience of the city.

Historical sustainability is a field within the definition of sustainability that too often is overlooked in preference focus on other aspects of the definition. Maintaining historical sustainability is important to maintain the visual and cultural values of community and society now where local identities are treated by the constant growth of globalized western culture (Tartaglia \& Rossi, 2015).

\section{Discussion}

As a design process the research achieved the objective to raise awareness of the issues affecting urban centers and the impact of these on the environment proportional to the increasing nature of urban consumption. Designing cities for the ecological age thought sustainable design tools such as biomimicry will be an essential set of skills for the urban designers of tomorrow. However, the resistances some architects have include public space as an element of the continuous productive urban landscapes. Or the resistance to consider ecological thinking reveals the challenges sustainable design must confront in contemporary urban design. As some of the participant designers associated biomimicry in architecture as a form of style that contributes little to the creation of urban value that they defined as in economic terms instead of the sought after environmental benefits. The resistance to ecological thinking or its perception as dogma evokes the statements made by Rem Koolhas and Susannah Hagan when the first stated that "architecture has a serious problem today" (Budds, 2018) or when the later in ecological urbanism, describes the way contemporary architects resist ecological limits (Hagan, 2014). The experienced resistance to employ biomimetic principles applied into architecture reveals the importance of raising awareness of the delicate environmental state urban societies operates on. Academia can no longer ignore the science behind sustainable design. As Hagan stated "architecture can't become the style for the rich and famous. If designers are unequipped, architecture is finished as a profession with any influence on the improved fu- 
ture of cities" (Hagan, 2014: p. 31).

\section{Conclusion}

This paper analyzed urban agricultural practices and how a more integrating public space with an inclusive approach with communities could benefit stakeholders, users and the environment. The paper also analyzed the different ways where the current agricultural paradigm is the biggest cause of pollution and environmental destruction and how this activity sustains urban life and their ever-growing populations. It is imperative that new agricultural paradigms are contemplated and moved within urban centers, from the new urban agricultural vertical farming stands out for a number of benefits such as being 30 times more efficient than other farming techniques, the accelerated speed of growth, short distances and space. However, many vertical farms had shut their doors due to the high operation costs. As we stated in this paper, one of the reasons for the high operation costs is the fact that vertical farms depend largely on technological components and large amounts of electricity to function and getting rid of unnecessary personnel. The proposed architectural direction to address these issues involves a "democratization" of vertical farming by integrating it in public space as a way to increase public participation in urban agricultural activities and raising awareness of the state of affairs regarding urban sustainability, food security for the future and environmental recovery to curve the effects of climate change. On the process of this "democratization", certain concessions must be made in order to allow increased access to vertical farming. The output may be affected but the environmental and social benefits that are expected to outweigh the loss accounted for reduced production. As humanity had progressively turned into an urban space, it's also important to improve the conditions of the built environment. For these purposes, it's necessary to increase the offer of ecological services and to raise environmental complexity in cities. Agricultural productive public space is required to be developed in a sustainable and integrationist framework by involving communities at risk into the urban farming process along other urban stakeholders. By allowing urban agricultural public space to function as social-ecological condensers, community members of all backgrounds (office workers, residents, commuters, students and especially rural migrants) can share their agricultural expertise and pass it onto others. This could keep new agricultural paradigms sustainable and inclusive. Agricultural productive public spaces are not conceived to be a replacement for proper open green areas such as parks and urban forest reserves, but as a complement to increase the environmental output in cities through specific interventions aimed at local improvement. an intervention of urban acupunctures that one to one manage to create a network of agrarian parks that improve quality of life, the quality of the air, food and reduce the dependence on rural agricultural production and the significant environmental impact it represents. 


\section{Conflicts of Interest}

The authors declare no conflicts of interest regarding the publication of this paper.

\section{References}

Abdolreza, A. (2011). World Food Prices Reach New Historic Peak. http://www.fao.org/news/story/en/item/50519/icode

Akemine, T. (1999). Alternative Urban Development and Farming: The Role of Urban Agriculture in Japan. Gate: Technology and Development, No. 2, 21-24.

Almansuri, A., Curwell, S., \& Dowdle, D. (2009). Urban Sustainability through Public Architecture.

Auge, M. (1992). Non-Places: An Introduction to Anthropology of Supermodernity (p. 79). Paris: Le Seuil.

Ayman, F., Weaam, Z., \& Khaled, D. (2013). The Art of Sustainability: The Dialectic Relation between Sustainable Performance and Performance of Sustainability. In International Conference on Sustainable Development in Building and Environment (pp. 1-3). Chongqing, 25-28 October 2013.

Balamou, E., Efstathiadou, T., Maimaris, A., Papageorgiou, G., \& Xergia, S. (2018). Examining Ways to Enhance Active Transportation and the Impact on Commuters' Health, Wellbeing and Sustainable Development. PeerJ Preprints, 6, e26690v1.

Besthorn, F. (2012). Vertical Farming Social Work and Sustainable Urban Agriculture in an Age of Global Food Crises. Australian Social Work, 66, 187-203. https://doi.org/10.1080/0312407X.2012.716448

Brown, K., \& Jameton, A. (2000). Public Health Implications of Urban Agriculture. Journal of Public Health Policy, 21, 22. https://doi.org/10.2307/3343472

Budds, D. (2018). Rem Koolhaas: Architecture Has a Serious Problem Today. https://www.fastcompany.com/3060135/rem-koolhaas-architecture-has-a-serious-prob lem-today

Calderon, C. (2012). Social Urbanism-Participatory Urban Upgrading in Medellin, Colombia. In R. Lawrence, H. Turgut, \& P. Kellett (Eds.), Requalifying the Built Environment: Challenges and Responses (p. 10). Göttingen: Hogrefe Publishing.

Choi, H. (2016). How Are Public Spaces Sustaining Cultural Identities in the Context of China's Increasingly Globally Focused Urban Developments: Using a Case Study of Putuo in Shanghai. Journal of Architecture and Urbanism, 40, 198-205. https://doi.org/10.3846/20297955.2016.1210045

Delang, C. (2017). Causes and Distribution of Soil Pollution in China. Environmental \& Socio-Economic Studies, 5, 1-17. https://doi.org/10.1515/environ-2017-0016

Despommier, D. (2010). The Vertical Farm. Feeding the World in the XXI Century (p. 159). New York: Picado Press.

Fadiman, M. (2016). Environmental Justice and the Lawn: Urban Parks in Shanghai, China. Florida Geographer, 47, 1-21.

Gallagher, M. (2018). USDA Defines Food Deserts. http://americannutritionassociation.org/newsletter/usda-defines-food-desert

Gaubatz, P. (2008). New Public Space in Urban China: Fewer Walls, More Malls in Beijing, Shanghai and Xining. China Perspectives, 4, 72-83.

Hagan, S. (2014). Ecological Urbanism: The Nature of the City (p. 31). Abing- 
don-on-Thames: Routledge.

Harvey, D. (2008). The Right to the City. New Left Review, 53, 9.

Herrmann, M. (2015). The Modern Day Victory Garden. Procedia Engineering, 118, 647-653. https://doi.org/10.1016/j.proeng.2015.08.498

Huang, P. (1993). Public Sphere and "Civil Society" in China? The Third Realm between State and Society. Modern China, 19, 216-240. https://doi.org/10.1177/009770049301900207

Imparato, I., \& Ruster, J. (2003). Slum Upgrading and Participation: Lessons from Latin America. Washington DC: World Bank. https://doi.org/10.1596/0-8213-5370-5

Janik, J. (2002). Ancient Egyptian Agriculture and the Origins of Horticulture. Acta Horticulturae, 582, 1. https://doi.org/10.17660/ActaHortic.2002.582.1

Kim, B., Poulsen, M., Margulies, J., Dix, K., Palmer, A., \& Nachman, K. (2014). Urban Community Gardeners' Knowledge and Perceptions of Soil Contamination Risks. PLoS ONE, 9, e87913. https://doi.org/10.1371/journal.pone.0087913

Kim, S., \& Kwon, H. (2018). Urban Sustainability through Public Architecture. Sustainability, 10, 1249. https://doi.org/10.3390/su10041249

Lancione, M. (2013). Introduction: Telescopic Urbanism and the Urban Poor: Symposium. City: Analysis of Urban Trends, Culture, Theory, Policy, Action, 17, 474-475. https://doi.org/10.1080/13604813.2013.829638

Li, J., Wang, Y., \& Song, Y. (2008). Landscape Corridors in Shanghai and Their Importance in Urban Forest Planning. In M. M. Carreiro, Y. C. Song, \& J. Wu (Eds.), Ecology, Planning, and Management of Urban Forests (p. 21). New York: Springer.

Mc Clintock, N. (2010). Why Farm the City? Theorizing Urban Agriculture through a Lens of Metabolic Rift. Cambridge Journal of Regions, Economy and Society, 3, 191-207. https://doi.org/10.1093/cjres/rsq005

McLennan, J. (2004). The Philosophy of Sustainable Design: The Future of Architecture (p. 4). Kansas: Ecotone Publishing Company.

Michael, C. (2017). 9 Reasons Why Vertical Farms Fail. Laramie, WY: Upstart University. https://university.upstartfarmers.com/blog/9-reasons-why-vertical-farms-fail

Nasr, J., Ratta, A., \& Smit, J. (2001). Benefits of Urban Agriculture. In Urban Agriculture Food, Jobs and Sustainable Cities (p. 11). New York, NY: United Nations Development Programme.

Ozak, A. (2015). Envisioning a Sustainable City: The Practice and Paradigm of Urban Farming in Shanghai. Master Dissertation, Shanghai: Tongji University.

Parikh, J., Parikh, K., Sunir, G., Painuly, J., Saha, B., \& Shukla, V. (1991). Consumption Patterns: The Driving Force of Environmental Stress (pp. 1-3). Bombay: Indura Ghandi Institute of Development Research.

Pawlyn, M. (2016). Biomimicry in Architecture (2nd ed., p. 129). Newcastle: RIBA Publishing.

Perez, V. M. (2014). Study of the Sustainability Issue of Food Production Using Vertical Farm Methods in an Urban Environment within the State of Indiana. Master's Thesis, West Lafayette, IN: Purdue University.

Phillips, J. (2006). The Willows Are Bending (p. 94). New York: Vantage Press.

Plasencia, M. (2019). Toshiko Mori: La arquitectura debe ser sostenible o terminará destruyendo el planeta.

Poe, M., Lecompte, J., Mclain, R., \& Hurley, P. (2014). Urban Foraging and the Relational 
Ecologies of Belonging. Social \& Cultural Geography, 15, 901-919. https://doi.org/10.1080/14649365.2014.908232

Pollack, R., Wood, S., \& Smith, K. (2010). An Analysis of Fossil-Fuel Dependence in the United States with Implications for Community Social Work. Critical Social Work, 11, 140-154.

Porter, N. (2011). When Grass Isn't Greener: Alternatives to the Perfect Lawn, at Home and at Harvard. https://harvardmagazine.com/2011/03/when-grass-isnt-greener

Robinson, J. (2006). Institution and Home: Architecture as a Cultural Medium (p. 11). PhD Thesis, Delft: Delft University of Technology.

Rowe, C., \& Koetter, F. (1978). Collage City (p. 136). Cambridge, MA and London: MIT Press.

Ruan, Y., Zhang, C., \&. Zhang, J. (2014). Shanghai Shikumen (pp. 32-33). Shanghai: Shanghai People's Fine Arts Publishing House.

Schumacher, P. (2010). The Autopoiesis of Architecture, Volume I: A New Framework for Architecture (p. 380). London: John Wiley \& Sons Ltd.

Sennett, R. (1977). The Fall of Public Man (p. 10, 20, 23). New York: Alfred A. Knopf.

Shen, Y., Sun, F., \& Che, Y. (2017). Public Green Spaces and Human Wellbeing: Mapping the Spatial Inequity and Mismatching Status of Public Green Space in the Central City of Shanghai. Urban Forestry \& Urban Greening, 27, 59-68.

https://doi.org/10.1016/j.ufug.2017.06.018

Siegner, A., Sowerwine, J., \& Acey, C. (2018). Does Urban Agriculture Improve Food Security? Examining the Nexus of Food Access and Distribution of Urban Produced Foods in the United States: A Systematic Review. Sustainability, 10, 2988.

https://doi.org/10.3390/su10092988

Tartaglia, S., \& Rossi, M. (2015). The Local Identity Functions in the Age of Globalization: A Study on a Local Culture. Community Psychology in Global Perspective CPGP, 1, 105-121.

Tasgal, P. (2016). The Economics of Local Vertical and Greenhouse Farming Are Getting Competitive.

https://agfundernews.com/the-economics-of-local-vertical-and-greenhouse-farming-ar e-getting-competitive.html

UN Department of Economic and Social Affairs (UNDESA) (2010). World Urbanization Prospects: The 2009 Revision, Executive Summary. New York: United Nations.

United States Environmental Protection Agency (2011). Reusing Potentially Contaminated Landscapes: Growing Garden in Urban Soils.

World Bank (2012). Food Prices, Nutrition, and the Millennium Development Goals, Poverty and Food Price Developments (p. 29). Global Monitoring Report. https://doi.org/10.1596/9780821394519_CH01 